\title{
Influence of Inorganic Nutrients and Panchagavya on Growth Attributes of Direct Seeded Rice
}

\author{
M. Sai Kumar, M. Sarvana Perumal, G. Murugan, \\ M. Vikram Sai, B. Maheswara Reddy \\ Department of Agronomy, Faculty of Agriculture, Annamalai University, \\ Annamalai Nagar, Chidambaram-608 002, Tamil Nadu, India.
}

Received: June 2021

Accepted: August 2021

\begin{abstract}
Background: Panchagavya is an organic formulation made from cow goods. The usage of fermented organic formulation with supportive beneficial microorganisms as foliar nourishment has come into the picture of modern agriculture for giving raise to good quality of non-residue protected food.

Methods: A field experiment was conducted from June to October 2020 at Farmer's field to study the Influence of Inorganic nutrients on Panchagavya on growth attributes of direct seeded Rice (BPT 5204). The experiment was laid out in a Factorial Randomized block design in which factor A consists of Inorganic nutrients and Factor B consists of Panchagavya at different doses and time of applications. Factor $A$ consists of viz., $A_{1} 100 \%$ RDF, $A_{2} 75 \%$ RDF and $A_{3} 50 \%$ RDF and Factor $B$ consists of $B_{1}$ No spraying, $B_{2}$ Panchagavya $3 \%$ Spraying at 15,30 and 45 DAS, $B_{3}$ Panchagavya $3 \%$ Spraying at 10, 20, 30 and 45 DAS, $B_{4}$ Panchagavya 4\% Spraying at 15, 30 and 45 DAS $_{5}$ Panchagavya 4\% Spraying at $10,20,30$ and 45 DAS.

Result: The results of the study revealed that the application of $100 \%$ Inorganic nutrients along with the foliar application of Panchagavya @ 4\% at 4 times spraying showed the highest plant height, Number of effective tillers and leaf area index.
\end{abstract}

Key words: Foliar application, Panchagavya, Rice.

\section{INTRODUCTION}

Rice (Oryza sativa L.) is one of the most staple food crops that is being extensively cultivated in India. India ranks second in rice cultivation grown in an area of 44 million hectares with a production of 101.56 million tonnes and productivity of $3.86 \mathrm{t} \mathrm{ha}^{-1}$. Andhra Pradesh ranks eight in terms of the nation's rice-growing area (2.16 million ha) but eight in terms of rice production (12.25 million tonnes) as of 2019. Manual transplanting is quite expensive, laborious and time-consuming and causes a lot of drudgeries. Manual transplanting takes about 300 to 350 man-hours ha ${ }^{-1}$ which is roughly $25 \%$ of the total labour requirement of the crop (Goel et al., 2008). Direct seeding is a successful method of rice cultivation in some countries (Adair et al., 1992), which saves labour and is more economical than transplanting. Direct seeding also provides good stand establishment in addition to water economy (Sharma 1995; Pandey et al., 2002). Direct seeded rice culture is an alternative costeffective technology that requires less labour and water than conventional transplanted rice. Comparable rice yield in the dry direct-seeded rice system and low input demand justifies the higher output to input ratio. Application of inorganic nutrients like nitrogen, phosphorus and potassium are the key nutrients that greatly influence the yield of crops. In addition, integration of organic with inorganic fertilizers improves the physiological system of the crop, provides adequate growth-regulating substances and modifies soil physio - chemical behaviours and results in augmented crop yields (Vimalendran and Wahab 2013). Physico-chemical properties of Panchagavya revealed that they possess almost all the major nutrients, micronutrients and growth hormones (IAA and GA) required for crop growth. The predominance of fermentative microorganisms like yeast and lactobacillus might be due to the combined effect of low $\mathrm{pH}$, milk products and the addition of jaggery/sugarcane juice as a substrate for their growth. In view of the above considerations, the present study was conducted to examine the Influence of Inorganic nutrients and Panchagavya on growth attributes of direct seeded rice.

\section{MATERIALS AND METHODS}

A field experiment was conducted during Kharif season June to October 2020, to study the Influence of Inorganic nutrients and Panchagavya on direct seeded rice. The soil of the field was clay loamy and soil $\mathrm{pH}$ was 7.0 and the soil fertility status was Medium in available nitrogen $\left(240 \mathrm{~kg} \mathrm{ha}^{-1}\right)$, high in available Phosphorus (148 $\mathrm{kg} \mathrm{ha}^{-1}$ ) and low in available potassium $\left(77 \mathrm{~kg} \mathrm{ha}^{-1}\right)$. The experiment was laid out in Factorial Randomized block design with fifteen treatment combinations in experimental plot sized $4 \times 5 \mathrm{~m}$ and replicated thrice. Buffer channels were made around each plot so as to serve as irrigation cum drainage channel. 


\section{Factor A}

$A_{1}-100 \%$ RDF

$A_{2}-75 \%$ RDF

$A_{3}-50 \% R D F$

\section{Factor B}

$B_{1}$ - No Spraying

$\mathrm{B}_{2}$ - Panchagavya $3 \%$ Spraying at 15,30 and 45 DAS

$\mathrm{B}_{3}$ - Panchagavya 3\% Spraying at 10, 20, 30 and 45 DAS

$\mathrm{B}_{4}$ - Panchagavya $4 \% 3$ Spraying at 15,30 and 45 DAS

$\mathrm{B}_{5}$ - Panchagavya 4\% Spraying at 10, 20, 30 and 45 DAS

The rice variety of BPT 5204 was sown on June $28^{\text {th }}$. The seeds were broadcasted with a depth of $3 \mathrm{~cm}$. Thinning was done 10 days after sowing to maintain the optimum population. The solution will be ready for spraying after 30 days. The recommended dose of $120: 40: 40 \mathrm{~kg} / \mathrm{ha}$ was adopted for $100 \%$ and from that $75 \%$ and $50 \%$, NPK was calculated and were applied to the plots as per the treatment schedule. The Panchagavya solutions were prepared as per the treatment schedule and were sprayed on 10, 20, 30 and 45 DAS by using water @500 mL/ha with the help of a knapsack sprayer. All the data observations recorded in the experiments were statistically analysed as suggested by Panse and Sukhatame (1978). The critical differences were worked out at a $5 \%$ probability level.

\section{RESULTS AND DISCUSSION Plant height}

The plant height was recorded at Tillering, Panicle initiation and Harvest stage. The height was significantly affected by different treatments. At the harvest stage, various treatments influenced the plant height significantly. The highest plant height was observed in the treatment $A_{1} B_{5} 100 \%$ RDF along with application of Panchagavya $4 \%$ spraying at 10, 20, 30 and 45 DAS. This treatment was found to superior and recorded the plant height of $(93.73 \mathrm{~cm})$ at harvest being par with the application of $100 \%$ RDF along with application of Panchagavya 4\% Spraying at 10, 30 and 45 DAS as shown in Table 1. The application of $50 \%$ RDF + Panchagavya $4 \%$ spraying at 10, 20, 30 and 45 DAS resulted in a significant reduction in plant height in comparison to the 100\% RDF along with application of Panchagavya $4 \%$ spraying at 10 , 20,30 and 45 DAS at tillering, panicle initiation (38.56, 77.39, 93.73) and at harvest. The minimum plant height is 66.98 was recorded in the treatment treated with the $50 \%$ RDF without Panchagavya spray. Since Panchagavya was sprayed to foliage, the absorption of nutrients would have been on the higher side, thus encouraging quick growth and increased plant height as noticed (Yadav and Christopher Lourduraj 2006).

\section{No of effective tillers $/ \mathrm{m}^{2}$}

No of tillers was counted at different crop growth stages and it can be concluded the no of effective tillers increased up to Panicle initiation and declined thereafter at harvest. The possible reason might be the mortality of smaller and weaker tillers at later stages of growth. The treatment which is treated with $100 \%$ RDF along with application of Panchagavya $4 \%$ spraying at $10,20,30$ and 45 DAS $\left(A_{1} B_{5}\right)$ produced maximum no of tillers at all stages because of the application of chemical fertilizer along with Panchagavya resulted in a greater number of tillers. The easy transfer of nutrients to plants through the foliar spray of Panchagavya might be the reason for the enhancement of the number of productive tillers (Upadhay et al., 2018). Minimum number of tillers were found in the treatment of $50 \%$ RDF and without a spray of Panchagavya at Harvest (249.92) as shown in Table 2.

\section{Leaf area}

Leaf area index was taken three times at tillering, Panicle initiation and at Harvest stage. The highest leaf area was found in the treatment which is applied with the 100\% RDF along with the Panchagavya 4\% Spraying at 10, 20, 30 and 45 DAS (1.68) $\left(A_{1} B_{5}\right)$ being a par with treatment 100\% RDF along with Panchagavya 4\% Spraying at 15, 30 and 45 DAS $\left(A_{1} B_{4}\right)(1.65)$ as shown in Table 3. The lowest leaf area index was found in the treatment which is treated with 50\% RDF without spraying Panchagavya. The plants which are sprayed with Panchagavya showed invariably produce bigger leaves and develop a denser canopy (Tharmaraj K. 2011).

Table 1: Effect of inorganic nutrients and panchagavya spray on plant height of rice (Oryza sativa L.).

\begin{tabular}{|c|c|c|c|c|c|c|c|c|c|c|c|c|}
\hline \multirow{2}{*}{ Treatments } & \multicolumn{3}{|c|}{ Tillering stage } & \multirow{2}{*}{ Mean } & \multicolumn{3}{|c|}{ Panicle initiation } & \multirow{2}{*}{ Mean } & \multicolumn{3}{|c|}{ Harvest } & \multirow{2}{*}{ Mean } \\
\hline & $A_{1}$ & $A_{2}$ & $\mathrm{~A}_{3}$ & & $A_{1}$ & $A_{2}$ & $\mathrm{~A}_{3}$ & & $A_{1}$ & $\mathrm{~A}_{2}$ & $\mathrm{~A}_{3}$ & \\
\hline $\mathrm{B}_{1}$ & 32.12 & 30.80 & 27.29 & 30.07 & 69.22 & 65.47 & 56.05 & 63.58 & 81.98 & 77.75 & 66.98 & 75.57 \\
\hline $\mathrm{B}_{2}$ & 34.45 & 32.78 & 28.18 & 32.04 & 72.03 & 67.85 & 58.74 & 66.20 & 87.91 & 82.65 & 69.61 & 80.05 \\
\hline $\mathrm{B}_{3}$ & 35.16 & 33.83 & 29.90 & 32.96 & 73.29 & 68.41 & 59.02 & 66.90 & 88.39 & 83.71 & 70.15 & 80.75 \\
\hline $\mathrm{B}_{4}$ & 37.84 & 36.10 & 31.87 & 35.27 & 76.68 & 73.12 & 62.56 & 70.78 & 92.86 & 89.14 & 72.57 & 84.85 \\
\hline $\mathrm{B}_{5}$ & 38.56 & 36.98 & 32.72 & 36.09 & 77.39 & 74.09 & 63.78 & 71.75 & 93.73 & 90.39 & 73.55 & 85.89 \\
\hline \multirow[t]{2}{*}{ Mean } & 35.63 & 34.10 & 30.13 & & 73.72 & 69.78 & 60.03 & & 88.97 & 84.72 & 70.57 & \\
\hline & \multicolumn{2}{|c|}{ S.Ed } & \multicolumn{2}{|c|}{ C.D } & \multicolumn{2}{|c|}{ S.Ed } & \multicolumn{2}{|c|}{ C.D } & \multicolumn{2}{|c|}{ S.Ed } & \multicolumn{2}{|c|}{ C.D } \\
\hline A & \multicolumn{2}{|c|}{0.56} & \multicolumn{2}{|c|}{1.16} & \multicolumn{2}{|c|}{0.70} & \multicolumn{2}{|c|}{1.44} & \multicolumn{2}{|c|}{0.85} & \multicolumn{2}{|c|}{1.74} \\
\hline$B$ & \multicolumn{2}{|c|}{0.73} & \multicolumn{2}{|c|}{1.50} & \multicolumn{2}{|c|}{0.91} & \multicolumn{2}{|c|}{1.87} & \multicolumn{2}{|c|}{1.10} & \multicolumn{2}{|c|}{2.25} \\
\hline$A \times B$ & \multicolumn{2}{|c|}{1.27} & \multicolumn{2}{|c|}{2.59} & \multicolumn{2}{|c|}{1.58} & \multicolumn{2}{|c|}{3.24} & \multicolumn{2}{|c|}{1.90} & \multicolumn{2}{|c|}{3.90} \\
\hline
\end{tabular}


Table 2: Effect of inorganic nutrients and panchagavya spray on tillers of rice (Oryza sativa L.).

\begin{tabular}{|c|c|c|c|c|c|c|c|c|c|c|c|c|}
\hline \multirow{2}{*}{ Treatments } & \multicolumn{3}{|c|}{ Tillering stage } & \multirow{2}{*}{ Mean } & \multicolumn{3}{|c|}{ Panicle initiation } & \multirow{2}{*}{ Mean } & \multicolumn{3}{|c|}{ Harvest } & \multirow{2}{*}{ Mean } \\
\hline & $A_{1}$ & $\mathrm{~A}_{2}$ & $\mathrm{~A}_{3}$ & & $A_{1}$ & $\mathrm{~A}_{2}$ & $\mathrm{~A}_{3}$ & & $A_{1}$ & $\mathrm{~A}_{2}$ & $\mathrm{~A}_{3}$ & \\
\hline$B_{1}$ & 332.57 & 315.28 & 276.98 & 308.27 & 340.98 & 323.30 & 268.74 & 311.0 & 318.94 & 303.48 & 249.92 & 290.78 \\
\hline $\mathrm{B}_{2}$ & 351.89 & 333.99 & 286.88 & 324.25 & 362.37 & 343.25 & 286.24 & 330.62 & 337.68 & 320.15 & 265.42 & 307.75 \\
\hline $\mathrm{B}_{3}$ & 352.64 & 334.81 & 287.62 & 325.02 & 363.79 & 344.75 & 287.15 & 331.89 & 340.41 & 322.23 & 268.66 & 310.43 \\
\hline $\mathrm{B}_{4}$ & 372.38 & 354.39 & 297.54 & 341.43 & 383.77 & 363.40 & 304.87 & 350.68 & 374.11 & 356.29 & 284.32 & 338.24 \\
\hline $\mathrm{B}_{5}$ & 374.09 & 355.28 & 298.20 & 342.52 & 386.33 & 363.99 & 305.61 & 351.97 & 375.97 & 358.55 & 287.98 & 340.83 \\
\hline \multirow[t]{2}{*}{ Mean } & 356.71 & 338.75 & 289.44 & & 367.45 & 347.73 & 290.52 & & 349.42 & 332.14 & 271.25 & \\
\hline & \multicolumn{2}{|c|}{ S.Ed } & \multicolumn{2}{|c|}{ C.D } & \multicolumn{2}{|c|}{ S.Ed } & \multicolumn{2}{|c|}{ C.D } & \multicolumn{2}{|c|}{ S.Ed } & \multicolumn{2}{|c|}{ C.D } \\
\hline A & \multicolumn{2}{|c|}{3.44} & \multicolumn{2}{|c|}{7.02} & \multicolumn{2}{|c|}{3.51} & \multicolumn{2}{|c|}{7.18} & \multicolumn{2}{|c|}{3.32} & \multicolumn{2}{|c|}{6.80} \\
\hline B & \multicolumn{2}{|c|}{4.44} & \multicolumn{2}{|c|}{9.07} & \multicolumn{2}{|c|}{4.54} & \multicolumn{2}{|c|}{9.27} & \multicolumn{2}{|c|}{4.29} & \multicolumn{2}{|c|}{8.77} \\
\hline$A \times B$ & \multicolumn{2}{|c|}{7.69} & \multicolumn{2}{|c|}{15.71} & \multicolumn{2}{|c|}{7.86} & \multicolumn{2}{|c|}{16.06} & \multicolumn{2}{|c|}{7.44} & \multicolumn{2}{|c|}{15.20} \\
\hline
\end{tabular}

Table 3: Effect of inorganic nutrients and panchagavya spray on leaf area index of rice (Oryza sativa L.).

\begin{tabular}{|c|c|c|c|c|c|c|c|c|c|c|c|c|}
\hline \multirow{2}{*}{ Treatments } & \multicolumn{3}{|c|}{ Tillering stage } & \multirow{2}{*}{ Mean } & \multicolumn{3}{|c|}{ Panicle initiation } & \multirow{2}{*}{ Mean } & \multicolumn{3}{|c|}{ Harvest } & \multirow{2}{*}{ Mean } \\
\hline & $A_{1}$ & $A_{2}$ & $\mathrm{~A}_{3}$ & & $A_{1}$ & $\mathrm{~A}_{2}$ & $\mathrm{~A}_{3}$ & & $A_{1}$ & $\mathrm{~A}_{2}$ & $\mathrm{~A}_{3}$ & \\
\hline $\mathrm{B}_{1}$ & 1.26 & 0.93 & 0.81 & 1.00 & 2.14 & 1.55 & 0.97 & 1.55 & 1.18 & 0.92 & 0.74 & 0.95 \\
\hline $\mathrm{B}_{2}$ & 1.39 & 1.22 & 1.01 & 1.20 & 2.87 & 2.26 & 1.72 & 2.28 & 1.35 & 1.22 & 1.02 & 1.20 \\
\hline $\mathrm{B}_{3}$ & 1.42 & 1.23 & 1.03 & 1.22 & 2.90 & 2.31 & 1.76 & 2.32 & 1.37 & 1.24 & 1.04 & 1.22 \\
\hline $\mathrm{B}_{4}$ & 1.58 & 1.49 & 1.13 & 1.40 & 3.70 & 3.08 & 2.47 & 3.08 & 1.65 & 1.42 & 1.23 & 1.43 \\
\hline $\mathrm{B}_{5}$ & 1.60 & 1.51 & 1.15 & 1.42 & 3.74 & 3.12 & 2.51 & 3.12 & 1.68 & 1.47 & 1.24 & 1.46 \\
\hline \multirow[t]{2}{*}{ Mean } & 1.45 & 1.27 & 1.02 & & 3.07 & 2.46 & 1.88 & & 1.45 & 1.25 & 1.06 & \\
\hline & \multicolumn{2}{|c|}{ S.Ed } & \multicolumn{2}{|c|}{ C.D } & \multicolumn{2}{|c|}{ S.Ed } & \multicolumn{2}{|c|}{ C.D } & \multicolumn{2}{|c|}{ S.Ed } & \multicolumn{2}{|c|}{ C.D } \\
\hline A & \multicolumn{2}{|c|}{0.01} & \multicolumn{2}{|c|}{0.02} & \multicolumn{2}{|c|}{0.02} & \multicolumn{2}{|c|}{0.05} & \multicolumn{2}{|c|}{0.02} & \multicolumn{2}{|c|}{0.04} \\
\hline B & \multicolumn{2}{|c|}{0.01} & \multicolumn{2}{|c|}{0.03} & \multicolumn{2}{|c|}{0.03} & \multicolumn{2}{|c|}{0.06} & \multicolumn{2}{|c|}{0.02} & \multicolumn{2}{|c|}{0.05} \\
\hline$A \times B$ & \multicolumn{2}{|c|}{0.02} & \multicolumn{2}{|c|}{0.06} & \multicolumn{2}{|c|}{0.05} & \multicolumn{2}{|c|}{0.12} & \multicolumn{2}{|c|}{0.04} & \multicolumn{2}{|c|}{0.10} \\
\hline
\end{tabular}

\section{CONCLUSION}

In the view of above considerations, the present study revealed that the treatment which is treated with $100 \%$ RDF along with Panchagavya 4\% Spraying at 10, 20, 30 and 45 DAS recorded the higher plant growth, effective tillers and leaf area index compared to the treatment which is applied with 75 and 50\% RDF along with Panchagavya 3\% Spray on 15,30 and 45 DAS.

\section{REFERENCES}

Adair, C.R., Beachell, H.M., Jodon, N.E., David, C.C. and Jones, J.W. (1992). Comparative yields of transplanted and direct sown rice. Journal of American Society of Agronomy. 34(2): 129-137.

Goel, A.K., Behera, D. and Swain, S. (2008). Effect of sedimentation period on performance of rice transplanter. Agricultural Engineering International: The CIGR e-J. X: 1-13.

Pandey, S., Mortimer, M., Wade, L., Tuong, T.P., Lopez, K. and Hardy, B. (2002). Direct Seeding: Research Issues and Ppportunities. Los Baños, Philippines: International Rice Research Institute.
Panse, V.G. and Sukhatme, P.V. (1978). Statistical Methods for Agricultural Workers. ICAR, New Delhi. 68-75.

Sharma, A.R. (1995). Direct seeding and transplanting for rice production under flood-prone lowland conditions. Field Crop Research. 44(2-3): 129-137.

Tharmaraj, K. (2011). A critical review on Panchagavya - A boon plant growth. International Journal of Pharmaceutical and Biological Archives. 2(6): 1611-1614.

Updhyay, P.K., Avijit Sen., Prasad, S.K., Yashwant Singh, Srivastava, J.P., Singh, S.P. and Singh, R.K. (2018). Effect of Panchagavya and Recommended dose of fertilizers on growth, nutrient content and productivity of transplanted rice (Oryza sativa) under middle gangetic plain of India. International Journal of Agricultural Sciences. 88(6): 931-936.

Vimalendran, L. and Wahab, K. (2013). Effect of foliar spray of Panchagavya on yield attributes, yield and economics of baby corn. Journal of Agronomy. 12(2): 109-112.

Yadav, B.K. and Christopher L. (2006). Effect of organic manures and Panchagavya spray on yield attributes, yield and economics of rice. Crop Research. 31(1): 1-5. 